\title{
MECHANISMS OF RADIONUCLIDE-HYROXYCARBOXYLIC ACID INTERACTIONS FOR DECONTAMINATION OF METALLIC SURFACES
}

A.J. FRANCIS, C.J. DODGE, AND J.B. GILLOW

Brookhaven National Laboratory, Upton, NY 11973

G.P. HALADA AND C.R. CLAYTON

Department of Materials Science and Engineering, SUNY at Stony Brook, NY 11794

FINAL REPORT

PROJECT PERIOD: 10/1/98 TO 9/30/01

PROJECT NUMBER: 64946

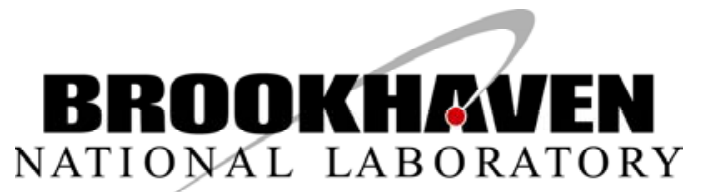




\section{TABLE OF CONTENTS}

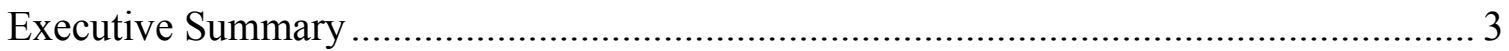

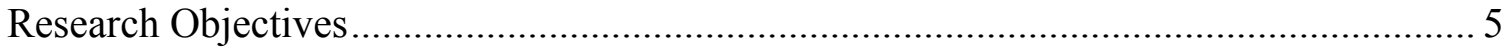

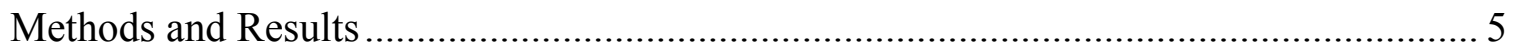

Relevance, Impact, and Technology Transfer ....................................................... 16

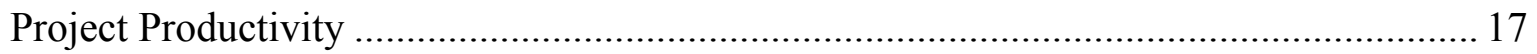

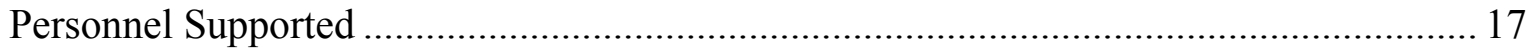

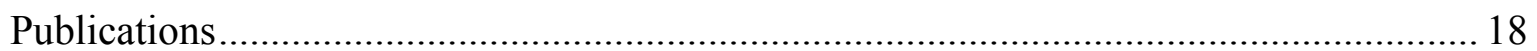

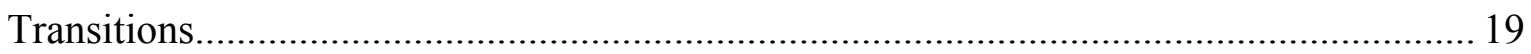

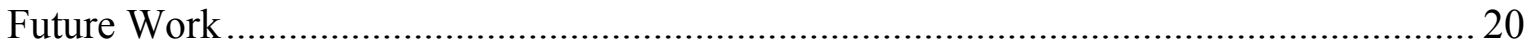

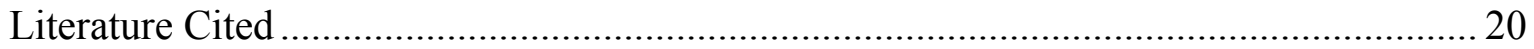

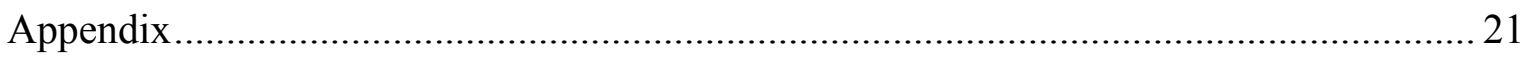




\section{EXECUTIVE SUMMARY}

In this EMSP program we investigated the key fundamental issues involved in the use of simple and safe methods for the removal of radioactive contamination from equipment and facilities using hydroxycarboxylic acids. Specifically, we investigated (i) the association of uranium with various iron oxides commonly formed on corroding plain carbon steel surfaces, (ii) the association of uranium with corroding metal coupons under a variety of conditions, and (iii) the decontamination of the uranium contaminated metal coupons by citric acid or citric acid formulations containing oxalic acid and hydrogen peroxide.

The association of uranium with the amorphous and crystalline forms of iron oxides commonly formed on corroding steel surfaces was determined by X-ray diffraction (XRD), Xray absorption near edge structure (XANES), Extended X-ray absorption fine structure (EXAFS), and X-ray photoelectron spectroscopy (XPS). Addition of uranium during the formation of ferrihydrite, goethite, green rust II, lepidocrocite, maghemite, and magnetite resulted in its incorporation with the oxides. XRD confirmed the mineralogical form of the oxide. EXAFS analysis of the oxides showed that uranium was present as a uranyl oxyhydroxide species with maghemite and magnetite, as a polyuranate species with goethite, as a bidentate inner-sphere complex with ferrihydrite, and as a trinuclear complex with lepidocrocite. Green rust II was converted to magnetite with concomitant reduction of the uranyl ion to its tetravalent form, confirmed by XANES and XPS. Iron was present as the ferric form with ferrihydrite, goethite, lepidocrocite, and maghemite; whereas with magnetite and green rust II both ferrous and ferric forms were present with the characteristic ferrous:ferric ion ratios of 0.65 and 0.73 , respectively. The rate and extent of $\mathrm{U}$ dissolution in $6 \mathrm{M} \mathrm{HCl}$ depended on its association with the oxide: uranium present as oxyhydroxide or polyuranate species underwent rapid dissolution followed by a slow dissolution of iron; while inner-sphere complexation of uranium with iron resulted in concomitant dissolution of the uranium and iron. A thorough understanding of the association of uranium with corrosion products at the molecular level is useful for the development of an appropriate decontamination process.

Low carbon steel coupons were either dipped in a dilute uranyl nitrate solution or contaminated through atomization of a uranyl nitrate solution onto the coupon surface following various times of accelerated corrosion in a high humidity chamber. Surface analyses of clean uncontaminated and uranium contaminated coupons were performed by Fourier Transform Infra Red (FTIR), X-ray photoelectron spectroscopy (XPS) and Rutherford back scattering (RBS) spectroscopy. All samples exposed to uranium showed a heterogeneous distribution of uranyl groups on the surface. Samples which were allowed to corrode further at $90 \%$ relative humidity for three days to one week following uranyl exposure showed some occlusion of the contaminant uranium by a loosely bound amorphous hydrated corrosion product. Surface areas covered by a thinner iron oxy-hydroxide corrosion layer showed stronger uranyl adsorption. RBS analysis indicated that uranium contamination was distributed throughout the upper $0.5 \mu \mathrm{m}$ of the corrosion product. The uranium-oxygen infrared stretching frequency was slightly shifted in areas rich in lepidocricite, indicating weaker bonding, whereas exposure to the acidic (uranyl) nitrate in solution resulted in an accelerated Fe corrosion product. 
The effectiveness of decontamination of U-contaminated steel coupons which have been exposed to uranyl ion and rusted or have undergone alternate cycles of $\mathrm{U}$ exposure and rusting were determined by using (i) oxalate- $\mathrm{H}_{2} \mathrm{O}_{2}$-citrate; or (ii) citrate- $\mathrm{H}_{2} \mathrm{O}_{2}$-citrate. Uranium removal efficiency varied from $68 \%$ to $94 \%$ depending on the extent of corrosion and the composition of the treatment solution. XPS and FTIR microspectroscopy analyses of the decontaminated coupons showed that small amounts of residual $\mathrm{U}$ remained occluded in heavily corroded areas. In regions where a thin yellow deposit was visible, FTIR indicated the presence of a Ucarboxylate with a mixed $4^{+} / 6^{+}$oxidation state. RBS studies of coupons before and after treatment showed occlusion of $\mathrm{U}$ by iron oxides.

Treatment of the decontaminated solution containing citric acid or citric and oxalic acids were accomplished by biodegradation followed by photodegradation. Pseudomonas fluorescens degraded citric acid but not oxalic acid. Iron precipitated from solution during biodegradation whereas uranium remained in solution complexed with the organic ligands. Uranyl -citrate and oxalate, which were recalcitrant to biodegradation, were readily photodegraded resulting in the precipitation and recovery of uranium as uranyl trioxide. 


\section{RESEARCH OBJECTIVES}

This project addresses key fundamental issues involved in the use of simple and safe methods for the removal of radioactive contaminants from slightly contaminated steel surfaces at the DOE sites so that the metals can be reused. The overall objectives of this research are to (i) determine the nature of the association of radionuclides such as uranium with plain carbon steel surfaces commonly found at sites targeted for decommissioning; (ii) selectively remove the radionuclides using hydroxycarboxylic acids (citric acid and its analogs) and (iii) elucidate the fundamental processes that could facilitate volumetric reduction of waste from Decommissioning and Decontamination (D\&D) activities and secondary waste minimization. The basic mechanisms involving coordination, complexation, dissolution and removal of uranium, and waste minimization with uranium recovery by biodegradation and photodegradation of secondary liquid waste streams were examined in a systematic manner.

\section{METHODS AND RESULTS}

This research was performed by Brookhaven National Laboratory (BNL) in collaboration with the State University of New York at Stony Brook (SUNY-SB). The associations of uranium with metal oxides typically formed on metallic surfaces, which have undergone oxidation characteristic of long term environmental exposures were investigated. We determined the rate and extent of radionuclide incorporation into amorphous and crystalline forms of iron oxides (ferrihydrite, goethite, green rust II, lepidocrocite, maghemite, and magnetite), and metallic coupons. Carbon steel coupons were exposed to uranium during and following accelerated atmospheric corrosion utilizing a cyclic humidity chamber . Advanced spectroscopic techniques X-ray photoelectron spectroscopy (XPS), X-ray near edge spectroscopy (XANES), Extended Xray absorption fine structure (EXAFS), Energy dispersive X-ray spectroscopy (EDX), Rutherford back-scattering spectroscopy (RBS), and both laboratory and synchrotron-based Fourier transform infra-red spectroscopy (FTIR) were used to characterize the (i) nature of the radionuclide association with the metal oxides and contaminated surfaces, and (ii) radionuclidecitrate complexes and mixed-metal (actinide-metal-citrate) complexes that have been removed from contaminated surfaces. In addition, we examined the microbial and photochemical degradation of the resulting actinide-organic complexes with application to recovery of radionuclides in a concentrated form and reduction of secondary waste generation.

Uranium Association with Iron Oxides Commonly Found on Corroding Metal Surfaces. We investigated the nature of association of uranium with various iron oxides commonly formed on corroding carbon steel surfaces (Dodge et al., submitted). Amorphous and crystalline forms of iron oxides ferrihydrite $\left(\mathrm{Fe}_{2} \mathrm{O}_{3} \mathrm{H}_{2} \mathrm{O}\right)$, goethite $(\alpha-\mathrm{FeOOH})$, green rust II, lepidocrocite $(\gamma-\mathrm{FeOOH})$, maghemite, and magnetite $\left(\mathrm{Fe}_{3} \mathrm{O}_{4}\right)$ were synthesized with and without uranium. The iron content of the oxides varied from 48 to $72 \%$. Essentially all of the added $U$ was incorporated in the oxide. The mineralogical form of the oxide was confirmed by X-ray diffraction. EXAFS analysis of the various oxides i.e., Fourier-transformed spectra for the oxides, the proposed structures for the uranium, and the corresponding fitting information for proposed structures are presented in Figure 1. The peaks in the figure represent a pseudo-radial distribution function for atoms in the near-neighbor region of uranium. The shells are uncorrected for phase shifts ( $\Delta \mathrm{R}=0.2-0.5 \AA$ depending on type of atom). The amplitude of the 

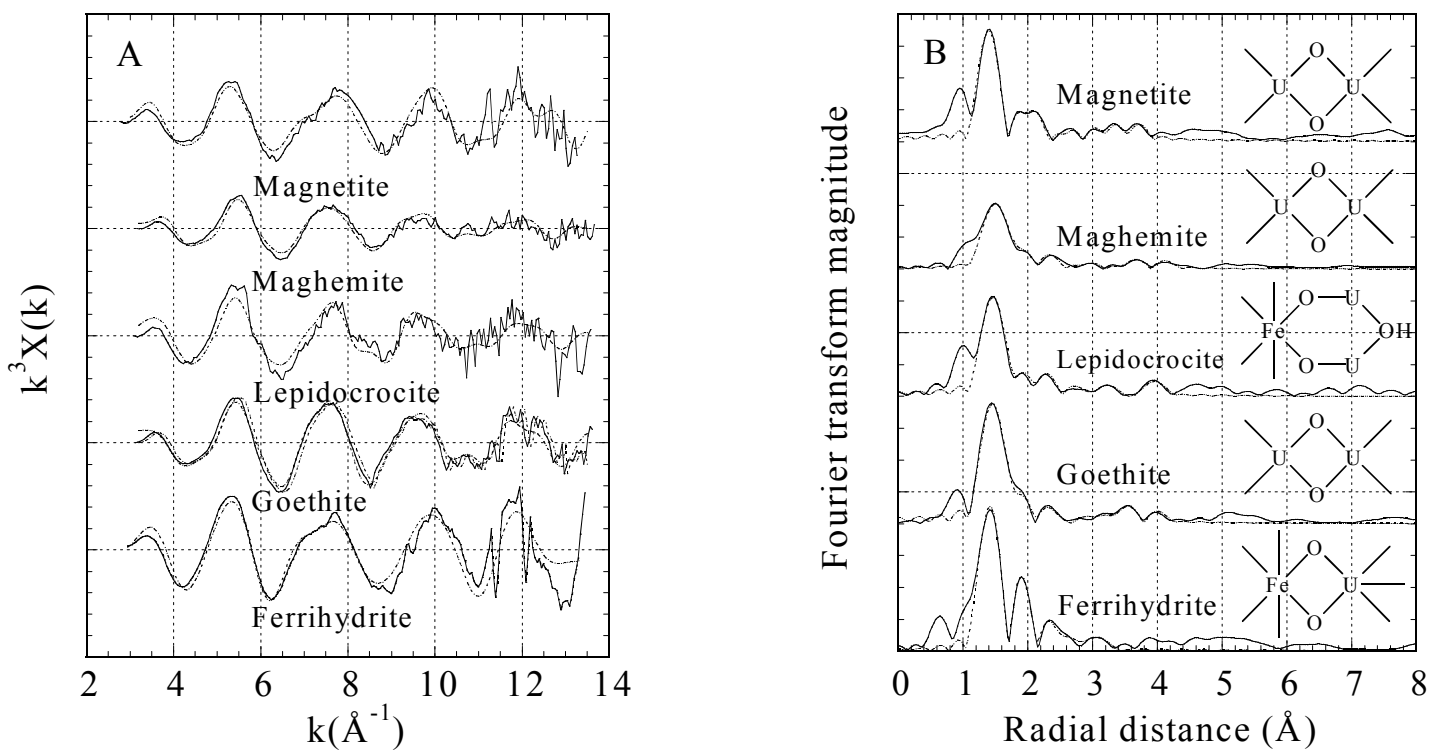

Figure 1. EXAFS spectra at the $\mathrm{U}_{\mathrm{III}}$ edge showing (A) filtered $\mathrm{k}^{3} \mathrm{X}$-weighted EXAFS spectra (2.9-13.3 $\left.\AA^{-1}\right)$, and (B) Fourier transform showing association of uranium with ferrihydrite, goethite, lepidocrocite, maghemite, and magnetite. Experimental data (-); theoretical fit (--).shells.

EXAFS signal provides information on coordination numbers for similar near-neighbor atoms. In the presence of more than one phase, average atomic information is obtained. The first shell distances are clustered in the range of 1.78 to $1.83 \AA$ and vary from 2.0 Os in magnetite to 2.4 Os in ferrihydrite. The second and third shells in each sample exhibit different ranges due to the type of oxygen bonding. Ferrihydrite has one large amplitude peak showing 3.0 equatorial Os at 2.35 $\AA$. Another peak at $2.54 \AA$ is due to the presence of 2.0 Os. The presence of a U-Fe interaction at $3.42 \AA$ indicates the uranium is bound to iron in bidentate fashion through the two oxygens. We compared the association of uranium coprecipitated with ferrihydrite to an aged ferrihydrite (Waite et al., 1994). Although the formation of a bidentate inner-sphere complex with iron is confirmed in both forms, there are distinct differences in the 2 O's in the U-O $\mathrm{eq}_{2}$ shell. A much smaller Debye-Waller factor (an indication of the thermal and static disorder in the atomic shell) for the coprecipitate (0.0010) compared to the aged form (0.0084) suggests that the U-O sites are more uniformly distributed during coprecipitation.

Uranium in goethite shows 2.3 axial oxygens at $1.82 \AA$, and a split equatorial oxygen shell containing 2.8 Os at $2.26 \AA$ and 1.7 Os at $2.51 \AA$. Two U-U interactions were noted at 3.66 $\AA$ and $4.19 \AA$; this suggests that a polyuranate species was formed, a finding consistent with the fitting parameters reported by others and us (Allen et al., 1996; Francis et al., 2000). Coprecipitation of uranium with goethite resulted in the formation of a polyuranate species. Polyuranates are characterized by their longer axial oxygen distances and shorter equatorial oxygen distances compared to uranyl ions (Wells, 1975). This was confirmed by the high 
binding energy observed by XPS (Moyes et al., 2000). The coprecipitation of the uraniummineral under alkaline conditions $(\mathrm{pH} 12)$ may have been a contributing factor to polyuranate formation since it is typically formed at high $\mathrm{pH}$. However, as noted by Misawa et al. (1972), goethite may also be formed under acidic conditions. No uranium association with the crystalline goethite as an inner-sphere complex was indicated as reported by Moyes et al. (2000).

The uranium in lepidocrocite is bonded to 2.3 axial Os at $1.82 \AA$. The equatorial shell is split, with 1.0 Os at $2.29 \AA$ and 2.5 Os at $2.53 \AA$. There is a U-Fe interaction at $3.52 \AA$ and a U-U interaction at $4.14 \AA$. The association of iron with uranium in the sample differs from that observed for ferrihydrite, with $0.5 \mathrm{Fe}$ atoms indicated in its structure. The few equatorial Os (3.5) as well as the small amount of $\mathrm{Fe}(0.5)$ suggest a shared bonding between iron and uranium. The structure we consider most reasonable is that of a trinuclear complex consisting of two uranium atoms bridged by a $\mu-\mathrm{OH}$ group, with each uranium atom forming an inner-sphere complex with iron. Lepidocrocite exhibited a unique association with uranium involving 3.5 equatorial oxygens, $0.5 \mathrm{Fe}$ atoms, and $1.0 \mathrm{U}$ atoms. The structure which best fits the data consists of a trinuclear complex with inner-sphere bonding of iron to two uranium atoms (Figure 1B). Moyes et al. (2000) proposed a bidentate inner-sphere complex with iron similar to that proposed for crystalline goethite. However, we noted no U-Fe interaction.

Uranium in magnetite has 2.0 Os at $1.78 \AA$ and an equatorial region containing two closely grouped sets of oxygen atoms with $1.9 \mathrm{Os}$ at $2.35 \AA$ and $1.8 \mathrm{Os}$ at $2.43 \AA$. We noted U-U interactions at 3.64 and $3.87 \AA$. Uranium in maghemite shows 2.2 axial Os at $1.83 \AA$, and equatorial oxygens consisting of 2.8 Os at $2.25 \AA$ and $1.7 \mathrm{Os}$ at $2.54 \AA$. The increase in oxygen content in the first equatorial shell compared to that in magnetite can be attributed to oxidation during synthesis. As with the parent compound, magnetite, there are two U-U interactions at 3.72 and $4.23 \AA$. The association of uranium with maghemite or magnetite has not been previously studied. We found that the coprecipitation of uranium with these oxides resulted in the formation of uranium hydroxide or oxyhydroxide species. The two U-U interactions at various distances are typical for precipitated uranium hydroxide as noted by Allen et al. (1996). The absence of U$\mathrm{Fe}$ interactions, indicate the uranium is most probably found in microcrystalline form on the oxide surface. The dissolution pattern of the uranium by dilute $\mathrm{HCl}$ supports this interpretation.

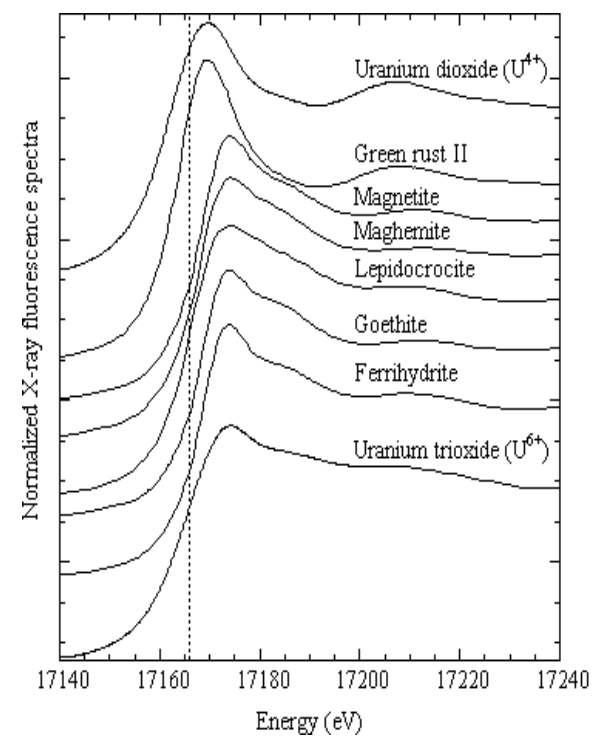

Figure 2. XANES spectra of normalized $\mathrm{U} \mathrm{L}_{\mathrm{III}}$ edges for uranium trioxide and $\mathrm{U}$ associated with iron oxides. The vertical line at $17166 \mathrm{eV}$ indicates the inflection point for $\mathrm{U}^{4+}$ species.
XANES Analysis. Figure 2 presents the XANES spectra for ferrihydrite, goethite, green rust II, lepidocrocite, maghemite, magnetite, and for the standards uranium dioxide $\left(\mathrm{U}^{4+}\right)$ and uranium trioxide $\left(\mathrm{U}^{6+}\right)$. The vertical line is set to the absorption edge for $\mathrm{U}^{4+}$ at $17166 \mathrm{eV}$. The shape and position of the XANES spectra for ferrihydrite, goethite, lepidocrocite, maghemite, and magnetite shows that uranium is predominantly present in the hexavalent form for these oxides. The spectra also exhibit two multiple scattering (MS) resonances at 20 and $60 \mathrm{eV}$ above the absorption edge that are diagnostic of the uranyl ion. However, the position of the absorption edge for the GR II sample is shifted to lower energy by $2 \mathrm{eV}$, identical to the shift observed for uranium dioxide standard, indicating the $\mathrm{U}$ is present in the tetravalent form. The absence of an MS peak at $20 \mathrm{eV}$ above the absorption edge is typical for this oxidation 
state.

The synthesis of GR II in the presence of U resulted in its reduction to tetravalent form with formation of magnetite. The stoichiometric decrease in the ratio of $\mathrm{Fe}$ (II) to $\mathrm{Fe}$ (III) from 0.73 in the absence of uranium to 0.62 confirms the role of ferrous ion in the reduction of uranium. Liger et al., (1999) have shown reduction of uranium occurs on suspensions of hematite in the presence of ferrous ion surface complexes $\equiv \mathrm{FeOFe}^{+}$and $\equiv \mathrm{FeOFeOH}^{0}$ at alkaline $\mathrm{pH}$. It was postulated that the surface complex provided a favorable coordination environment for electron transfer from iron to uranium. Brooks and coworkers (1986) observed that electric field induced deprotonation of GR II hydroxyl groups resulted in charge redistribution from univalent hydroxyl oxygen to divalent oxygen with oxidation of ferrous to ferric ion. This resulted in formation of lepidocrocite or goethite; similarly, deprotonation of green rust I resulted in akaganeite $(\beta-\mathrm{FeOOH})$ formation. The presence of cations and anions are also known to affect the formation of iron oxides. Ishikawa et al. (1999) demonstrated that addition of Co(II) and $\mathrm{Cu}(\mathrm{II})$ during synthesis of $\mathrm{Fe}(\mathrm{OH})_{2}$ resulted in production of magnetite and inhibited goethite crystallization; while the presence of $\mathrm{Cr}$ (III) exhibited the opposite effect. Using X-ray diffraction analysis Refait et al. (1998) established that the structure for a synthetically prepared green rust I consisted of $\mathrm{Fe}(\mathrm{OH})_{2}$ sheets alternating regularly with negatively charged interlayers of chloride ions and water molecules.

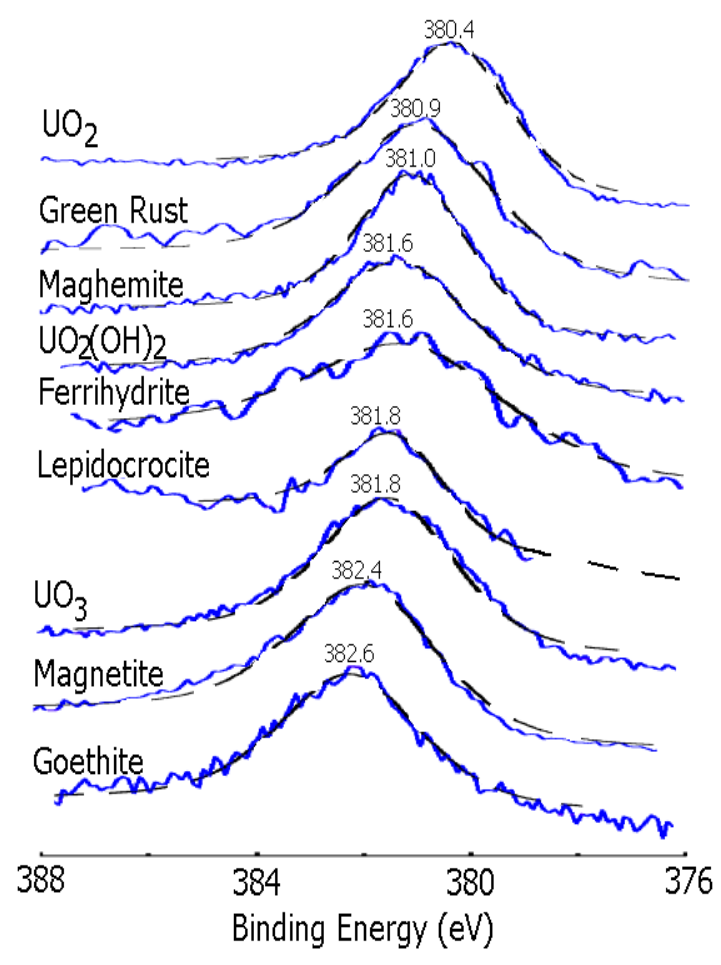

Figure 3. X-ray photoelectron spectroscopy (XPS) showing raw $(-)$ and fitted (---) $\mathrm{U}_{4} \mathrm{f}_{7 / 2}$ binding energy spectra for ferrihydrite, goethite, green rust II, lepidocrocite, maghemite, and magnetite and $\mathrm{UO}_{2}\left(\mathrm{U}^{4+}\right)$ and $\mathrm{UO}_{3} \quad\left(\mathrm{U}^{6+}\right)$ and $\mathrm{UO}_{2}(\mathrm{OH})_{2}\left(\mathrm{U}^{6+}\right)$ standards. standard. However, the U-Fe associated uranium oxides ferrihydrite and lepidocrocite show higher stretching frequencies that may reflect differences in the coordination of the uranium with iron. The two U atoms in lepidocrocite exhibit a trinuclear association with iron, while in green 
rust II uranium is in the tetravalent form which does not contain double-bonded axial oxygen groups. Allen et al., (1996) observed that the trend to greater average distances for uranium in the oxides should be reflected by decrease in the intensities of the absorption band due to lengthening of the equatorial oxygen atoms. However, our results show these frequencies are not

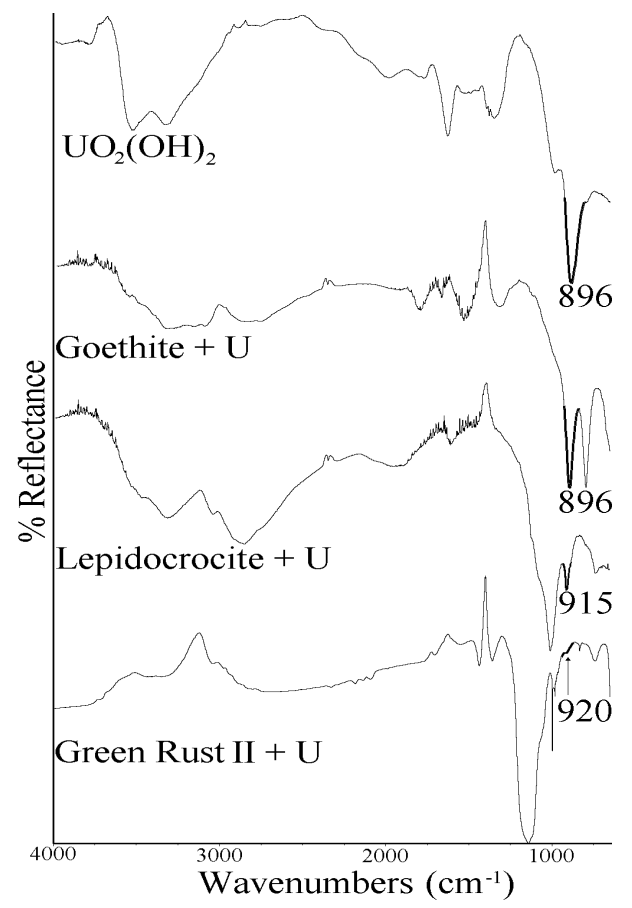

Figure 4. Fourier transform infrared absorption spectra for uranyl hydroxide, and goethite-, lepidocrocite-, and green rust II- containing uranium. The highlighted spectra $\left(896\right.$ to $\left.920 \mathrm{~cm}^{-1}\right)$ show the asymetric stretching fremencies for uranium in agreement with weighted uranyl equatorial oxygen distances obtained from EXAFS data. This information confirms that the bonding environment for each oxide is different.

Dissolution of Uranium Associated with Various Iron Oxides. The rate and extent of uranium dissolution from the various oxides was dependent upon its association. Uranium associated as oxyhydroxide or polyuranate species with goethite, maghemite, and magnetite, underwent rapid dissolution followed by a slow dissolution of iron. This was predominantly due to the association of uranium with the oxide surface. Uranium formed an inner-sphere bidentate complex with iron in ferrihydrite, and we observed concomitant dissolution of the uranium and iron. Lepidocrocite formed a trinuclear complex with two uraniums bonded by a $\mu$ $\mathrm{OH}$ bridging group and an inner-sphere bond with iron. As with ferrihydrite, there was concomitant removal of uranium and iron during dissolution of the matrix. However, this relationship may involve two competing mechanisms: (i) dissolution of the U-U bond, and (ii) dissolution of the inner-sphere U-Fe complex. The mechanism of uranium dissolution from green rust II could not be established because of the complexity of the oxide phase. Its rapid dissolution in dilute acid compared to the iron indicates it is probably present as a uranous oxyhydroxide species. These results suggest that an understanding of the nature of the radionuclide association with various oxides formed on corroding steel surfaces may aid in the development of appropriate decontamination technology.

Association of Uranium with Metal Surfaces. In this study the experimental methods were designed to provide a clear model of the interaction of contaminant uranium with atmospherically exposed metal surfaces typical of those found at former uranium processing sites, both before and after decontamination with hydroxycarboxylic acid. This model could then be compared to data from uranium co-precipitated with iron oxides typically formed on corroding metal surfaces. This work has shown that co-precipitation of uranyl species with magnetite, maghemite, lepidocrocite, goethite and ferrihydrite leads to appreciable uptake of uranium as U(VI), especially by the hydrated ferric oxides. It was found that co-precipitation leads to chemical incorporation of uranyl groups as a mixed uranium-iron oxyhydroxide, with a structure dependent on the corrosion compound analog which was synthesized. The uranium was no longer bound to nitrate, but remained in a hexavalent state (as shown by XPS) in all cases except for co-precipitation during synthesis of green rust I (which only forms in the presence of 
sulfate). In this case, reduction of hexavalent uranium to U(IV) was indicated primarily by XANES (XPS indicated reoxidation at the surface of the powder sample to hexavalent uranium). The study of the interaction of uranyl nitrate with the surface of corroding 1010 carbon steel coupons indicated some similarities, but also a number of differences. It is these differences especially which identify the need to investigate the nature of uranium interactions with the surfaces of corroded and non-corroded 1010 carbon in order to optimize a hydroxycarboxylic acid decontamination process. The primary analytical tools used to analyze these surfaces were X-ray Photoelectron Spectroscopy (XPS), both synchrotron and laboratory-based FTIR microspectroscopy, secondary electron microscopy (SEM), and Rutherford backscattering spectroscopy (RBS). The data collected indicate that the chemical and physical nature of uranium association with the surface depends on the initial conditions that the steel samples experienced prior to uranyl nitrate exposure. These initial conditions simulate realistic atmospheric corrosive conditions on uranium association with the surface, which in turn will likely affect the cleaning process.

Characterization of Steel Coupons Contaminated with Uranium. Low carbon steel coupons (1010) were obtained from a structural sheet steel supplier and were sheared into 6x6 inch sections, deburred, cleaned thoroughly with Alconox ${ }^{\mathrm{TM}}$ detergent to remove oils, and rinsed in double distilled water. Our choice in studying 1010 carbon steel is intentional because it is commonly used in industry as structural and load bearing steel and, ultimately, is one of the primary metals that will undergo a decontamination process. Five experimental contamination conditions were simulated, which are likely to be encountered at any site. The experimental parameters which were chosen to vary as part of the experimental design were (i) degree of initial atmospheric corrosion prior to contamination, (ii) degree of atmospheric corrosion following contamination, (iii) method of contamination, and (iv) concentration of contaminant.

These include:

1. Contamnination of non-corroded or lightly corroded structural steel. These samples were as received steel, bearing only an air formed corrosion layer (lightly corroded). This layer was found by use of XPS to be composed of $\mathrm{Fe}_{2} \mathrm{O}_{3}, \mathrm{FeOOH}$, and $\mathrm{Fe}_{3} \mathrm{O}_{4}$ - as the layer was very thin (optically transparent), infrared analysis (FTIR and SIRMS) showed no deltaectable corrosion product layer. Samples were analyzed before and after exposure to a uranyl nitrate solution, either by atomization or by dipping and drying. Atomization was conducted by placement in a HEPA filter fume hood and gently spraying twice with 10 or 40 $\mathrm{mM}$ uranyl nitrate solution to one side of each coupon using a variable spray pump attached to polycarbonate bottle.

2. Contamination of the corrosion product surface of mildly corroded structural steel. These mildly corroded samples included steel corroded through a cyclic humidity treatment. This sample was cleaned, then placed horizontally on a plastic rack in a specially constructed humidity chamber designed to maintain a relative humidity of $90-99 \%$ at 23 to 25 ${ }^{\circ} \mathrm{C}$. Wet/dry cycles were conducted on a 12 -hour basis (30 minute wet period and $11 \frac{1}{2}$ hours dry period) with continuous monitoring of humidity and temperature. Samples were analyzed before and after exposure to a uranyl nitrate solution, either by atomization or by dipping and drying.

3. Continued corrosion following contamination of as received structural steel. As received steel samples were exposed to uranyl nitrate solution, as described in experimental design (1) above, and then cyclically corroded as in design (2) above 


\section{Corrosion product layer formed on structural steel which had been contaminated}

after mildly corroded. These heavily corroded samples underwent additional cyclic corrosion of four to seven days duration following exposure of the first corrosion product layer to atomized uranyl nitrate solution.

5. Contaminant/corrosion product layer formed on a structural steel sample following repeated corrosion and contamination: These heavily corroded samples underwent initial $10 \mathrm{mM}$ uranyl nitrate exposure and humidity treatment of four days followed by a second uranium exposure and a final cyclic humidity treatment of seven days.

Table 1: Analysis of Samples using XPS, SIRMS, and FTIR

\begin{tabular}{|c|c|c|}
\hline Experimental Conditions & Physical Appearance & Results \\
\hline $\begin{array}{l}\text { 1. (a) Lightly corroded/as received; } \\
\text { dipped in } 10 \mathrm{mM} \text { or } 40 \mathrm{mM} \text { Uranyl } \\
\text { nitrate solution }\end{array}$ & Light to dark yellow & $\begin{array}{l}\text { XPS indicates hexavalent uranium, plus } \\
\mathrm{Fe}_{2} \mathrm{O}_{3}, \mathrm{FeOOH} \text { and ferrihydrite. } \\
\text { FTIR indicates } \gamma-\mathrm{FeOOH} \text { (lepidocrocite) } \\
\text { and characteristic } \mathrm{O}=\mathrm{U}=\mathrm{O} \text { peak from } 906 \\
\text { to } 912 \mathrm{~cm}^{-1} \text { (uranyl hydroxide) }\end{array}$ \\
\hline $\begin{array}{l}\text { 1. (b) Lightly corroded/as received; } \\
\text { atomized with } 10 \mathrm{mM} \text { or } 40 \mathrm{mM} \\
\text { Uranyl nitrate solution }\end{array}$ & $\begin{array}{l}\text { Low concentration } \\
\text { gives grayish } \\
\text { appearance; high } \\
\text { concentration produced } \\
\text { yellow color over most } \\
\text { of surface }\end{array}$ & $\begin{array}{l}\text { XPS indicates hexavalent uranium, plus } \\
\mathrm{Fe}_{2} \mathrm{O}_{3}, \mathrm{FeOOH}, \mathrm{Fe}_{3} \mathrm{O}_{4} \text { and ferrihydrite in } \\
\text { both cases. } \\
\text { FTIR indicates } \gamma-\mathrm{FeOOH} \text { and a } \mathrm{O}=\mathrm{U}=\mathrm{O} \\
\text { peak ranging from } 907 \text { to } 940 \mathrm{~cm}^{-1} \text { in the } \\
\text { case of low concentration }(10 \mathrm{mM} \text { ) } \\
\text { FTIR indicates } \gamma-\mathrm{FeOOH} \text { and } \alpha-\mathrm{FeOOH} \\
\text { (goethite), and a } \mathrm{O}=\mathrm{U}=\mathrm{O} \text { peak ranging } \\
\text { from } 895 \text { to } 915 \mathrm{~cm}^{-1} \text { in the high } \\
\text { concentration. }\end{array}$ \\
\hline $\begin{array}{l}\text { 2. Mildly corroded samples, } \\
\text { atomized with } 10 \mathrm{mM} \text { or } 40 \mathrm{mM} \\
\text { Uranyl nitrate solution }\end{array}$ & $\begin{array}{l}\text { Orange and brown, } \\
\text { roughness increases } \\
\text { with concentration of } \\
\text { uranyl in solution }\end{array}$ & $\begin{array}{l}\text { As in the first case, XPS indicates } \\
\text { hexavalent uranium and } \mathrm{Fe}_{2} \mathrm{O}_{3}, \mathrm{FeOOH}, \\
\mathrm{Fe}_{3} \mathrm{O}_{4} \text { and ferrihydrite. More uranium } \\
\text { tends to be retained than ion case } 1 \\
\text { above. } \\
\text { FTIR indicates } \gamma-\mathrm{FeOOH} \text { and } \alpha-\mathrm{FeOOH} \\
\text { and a } \mathrm{O}=\mathrm{U}=\mathrm{O} \text { peak ranging from } 900 \text { to } \\
928 \mathrm{~cm}^{-1}, \text { with some peaks indicative of } \\
\text { schoepite formation (crystallized uranyl } \\
\text { hydroxide). }\end{array}$ \\
\hline $\begin{array}{l}\text { 3. Corroded sample, atomized with } \\
40 \mathrm{mM} \text { Uranyl nitrate solution or } \\
\text { dipped in } 10 \mathrm{mM} \text { solution }\end{array}$ & $\begin{array}{l}\text { Orange and rough; } \\
\text { flaky }\end{array}$ & $\begin{array}{l}\text { XPS indicates hexavalent uranium and } \\
\mathrm{Fe}_{2} \mathrm{O}_{3}, \mathrm{FeOOH} \text { and ferrihydrite. } \\
\text { FTIR indicates crystalline } \gamma \text {-FeOOH. }\end{array}$ \\
\hline $\begin{array}{l}\text { 4. Corroded sample, atomized with } \\
40 \mathrm{mM} \text { Uranyl nitrate solution, and } \\
\text { then corroded for an additional 4-7 } \\
\text { days }\end{array}$ & Orange and rough & $\begin{array}{l}\text { FTIR indicates crystalline } \gamma \text {-FeOOH. } \\
\text { Similar to experiment design ( } 3 \text { ) above. }\end{array}$ \\
\hline $\begin{array}{l}\text { 5. Cyclic exposure/corrosion } \\
\text { sample (heavily corroded) }\end{array}$ & $\begin{array}{l}\text { Orange and brown, } \\
\text { flaky }\end{array}$ & $\begin{array}{l}\text { XPS indicates hexavalent uranium plus } \\
\mathrm{Fe}_{2} \mathrm{O}_{3}, \mathrm{FeOOH} \text {, ferrihydrite. } \\
\text { FTIR indicates } \gamma \text {-FeOOH and } \alpha-\mathrm{FeOOH} \text {. }\end{array}$ \\
\hline
\end{tabular}


Implications of this analysis are important. In summary, we found that the corrosion layers formed on the samples were not always homogeneous, and the results suggest that corrosion conditions play a major role in their chemical composition. The typical corrosion product layer initially formed on contaminated 1010 carbon steel is primarily composed of an upper layer of oxyhydroxide, mainly lepidocrocite, and a layer near the metal surface composed of ferrihydrite, magnetite and maghemite. Exposure to atomized uranium contamination results in appearance of mixed valent Fe corrosion product at surface of corrosion product layer, while the bulk of the corrosion product layer appears to change little due to contamination, especially in the case of low concentration exposure. High concentration exposure leads to formation of goethite in addition to lepidocricite. Continued or cyclic corrosion resulted in the formation of goethite and further oxidation of magnetite to maghemite. XPS analysis indicated that the uranium retained on the surface is present as oxidized $\mathrm{UO}_{2}{ }^{2+}$ in all samples studied, and FTIR analysis shows that the asymmetric $\mathrm{O}=\mathrm{U}=\mathrm{O}$ stretching frequency is affected by variations in coupon treatment. Uranium appears to be preferentially adsorbed on hydroxyl-rich or lepidocrocite-rich areas and well distributed within the corrosion layers, as shown by RBS. It was observed that uranium is no longer associated with nitrate (although trapped nitrate may exist in heavily corroded areas on some samples). Subsequent corrosion of contaminated samples leads to the formation of metaschoepite or schoepite, a more crystalline form of hydrated uranyl hydroxide. XPS and ICP-AES indicate that uptake of uranium increases when exposure occurs after rusting where more uranium resides on the surface and less is incorporated within the corrosion layers. These results suggest that heavily corroded areas are comprised of more crystallized forms of iron minerals, which increase the retention of uranium.

Decontamination of Uranium Contaminated Steel Coupons. The effectiveness of decontamination of U-contaminated coupons which have undergone alternate cycles of $U$ exposure and rusting (ER/ER) by (i) citric acid alone; (ii) oxalic acid-hydrogen peroxide-citric acid; or (iii) citric acid-hydrogen peroxide-citric acid treatment has been determined. The amount of uranium removal was dependent on the extent of corrosion on the coupon surface. The efficiency of $U$ removal for the treatment processes are presented in Table 2.

Table 2. Efficiency of uranium removal from contaminated steel coupons.

\begin{tabular}{lccc}
\hline \multirow{2}{*}{ Treatment } & \multicolumn{3}{c}{ Uranium removed (\%) } \\
\cline { 2 - 4 } & Mild corrosion & Moderate corrosion & Heavy corrosion \\
\hline Citric acid & nd & nd & $63.6 \pm 3.2$ \\
Oxalate/peroxide/citrate & $94.2 \pm 1.5$ & nd & $67.6 \pm 3.2$ \\
Citrate/peroxide/citrate & $90.3 \pm 2.6$ & $72.8 \pm 2.4$ & $71.5 \pm 1.0$ \\
\hline nd - not determined & & &
\end{tabular}


Citric acid alone treatment resulted in removal of $63.6 \%$ of the $U$ from a heavily corroded sample. The efficiency of $U$ removal using oxalic acid-hydrogen peroxide-citric acid varied from $94.2 \%$ in a lightly corroded coupon to $67.6 \%$ from a heavily corroded coupon. Citric acidhydrogen peroxide-citric acid treatment removed $90.3 \%$ of the $U$ from a mildly corroded coupon, $72.8 \%$ from a moderately corroded coupon, and $71.5 \%$ from a heavily corroded coupon. The low carbon steel coupon before and after citric acid-hydrogen peroxide-citric acid treatment is shown in Figure 5. Decontaminated coupon clearly showed extensive removal of rust and uranium.
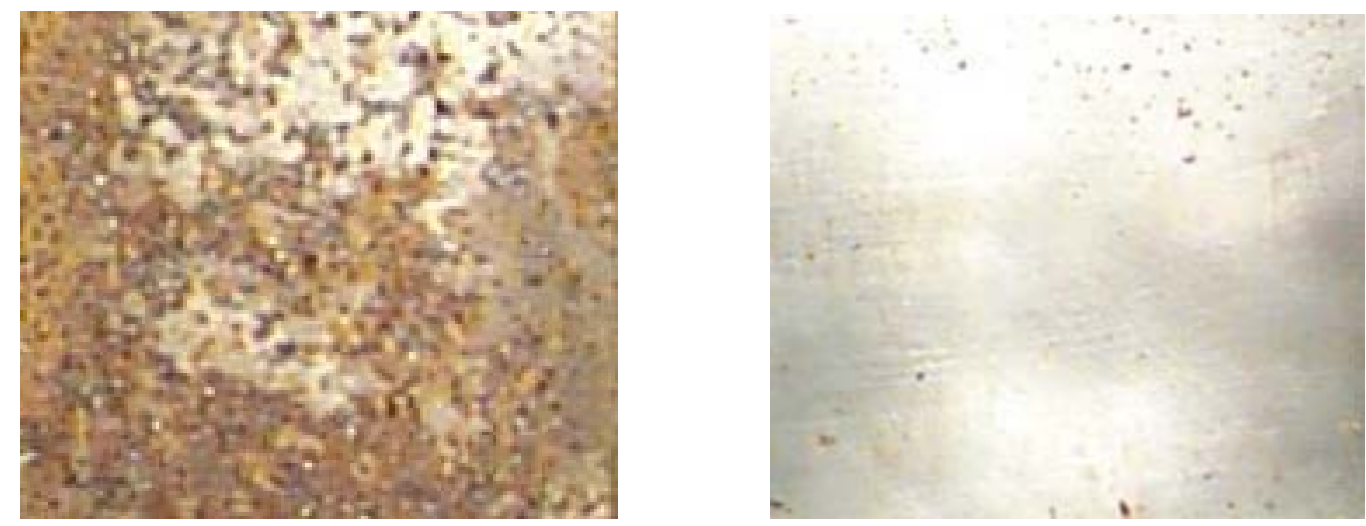

Figure 5. Low carbon steel coupons before and after treatment with citric acid-hydrogen peroxide-citric acid.

Rutherford backscattering analysis of cyclically rusted and exposed contaminated carbon steel coupons before and after citric acid treatment indicated that an average ratio of $300 \mathrm{Fe}$ to $\mathrm{U}$ atoms in the top 0.5 micron of corrosion product increases to an average of nearly $3000 \mathrm{Fe}$ to $\mathrm{U}$ atoms in the same range of depth following cleaning.

Surface analysis of low carbon steel coupons after decontamination. The results of surface analysis following decontamination are summarized as follows: After decontamination, a lightly corroded sample which had been exposed to uranyl contamination showed amorphous iron oxhydroxide on the surface as indicated by FTIR. XPS show the presence of both Fe(III) and Fe(II) species. The Fe(II) is most likely from the mix-valent magnetite. Both XPS and FTIR results indicate uranium is below detection limits, indicating that the cleaning process was effective. Carboxylate groups, most likely bound to iron, were also found on the surface, as indicated by XPS. Iron citrates may play an important role in protecting the steel from further corrosion.

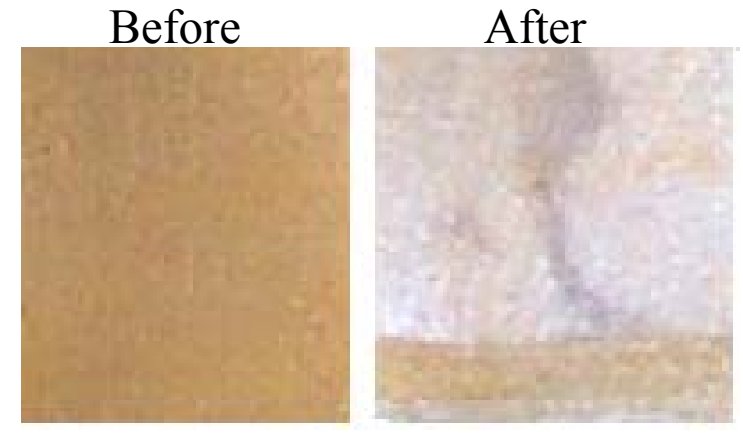

Exposed as-received (lightly corroded)
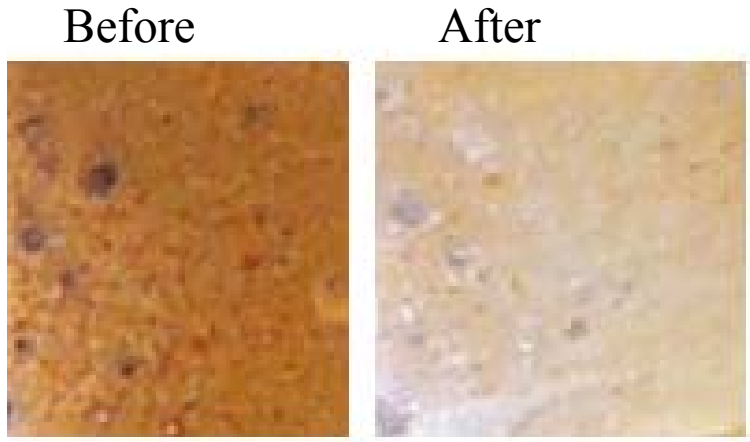

Cyclically exposed and corroded 
Figure 6: Carbon steel coupon samples before and after decontamination.

As for the heavily corroded sample, the corrosion products that remained even after decontamination were amorphous oxyhydroxides such as lepidocrocite and possibly goethite. Amorphous iron hydroxides may also have formed after the decontamination process, which involves rinsing the surface with distilled water. XPS data shows the predominance of Fe(III) species, with a smaller amount of Fe(II) species as compared to the lightly corroded sample. Again, carboxylate groups were found on the surface. The cyclically exposed sample also shows traces of uranium after cleaning, possibly due to spalling of the corrosion layers after decontamination, exposing some uranium underneath thick oxyhydroxide layers where the citric acid could not reach or surface uranium from u-citrate complexes that were not rinsed away by deionized water. XPS analysis of the contaminated, heavily corroded coupons following decontamination showed three species of carbon on the sample surface: adventitious hydrocarbon $(284.6 \mathrm{eV}) ;-\mathrm{CH}_{2} \mathrm{OH}(286.1 \mathrm{eV})$; and $-\mathrm{COOH}(288.2 \mathrm{eV})$. In addition, a small U4f peak could be detected. The $\mathrm{U}_{4 \mathrm{f}_{7 / 2}}$ binding energy of the residual contaminant was $382.2 \mathrm{eV}$, about $0.5 \mathrm{eV}$ lower than that of U(VI) from a uranyl or oxide standard. This likely represents a complexed U species incompletely removed from the surface by the decontamination process. The $\mathrm{Fe} 2 \mathrm{p}_{3 / 2}$ spectra indicates ferrous species $\left(\mathrm{Fe}^{2+}\right)$ were predominant. EDAX and RBS did indicate trace amounts of retained uranium, primarily in occluded, heavily corroded regions. This is likely due to poor access to these areas resulting in incomplete rinsing of carboxyl-bound uranium. In particular, RBS showed that uranium was still present in a heavily corroded area and well distributed within the upper micron of the corrosion product layer, indicating that the citric acid treatment was unable to decontaminate these areas. It is also possible that the uranium complex was more strongly bound to the crystalline corrosion products found in these areas, hindering chelation of the uranium by the citric ligand. 


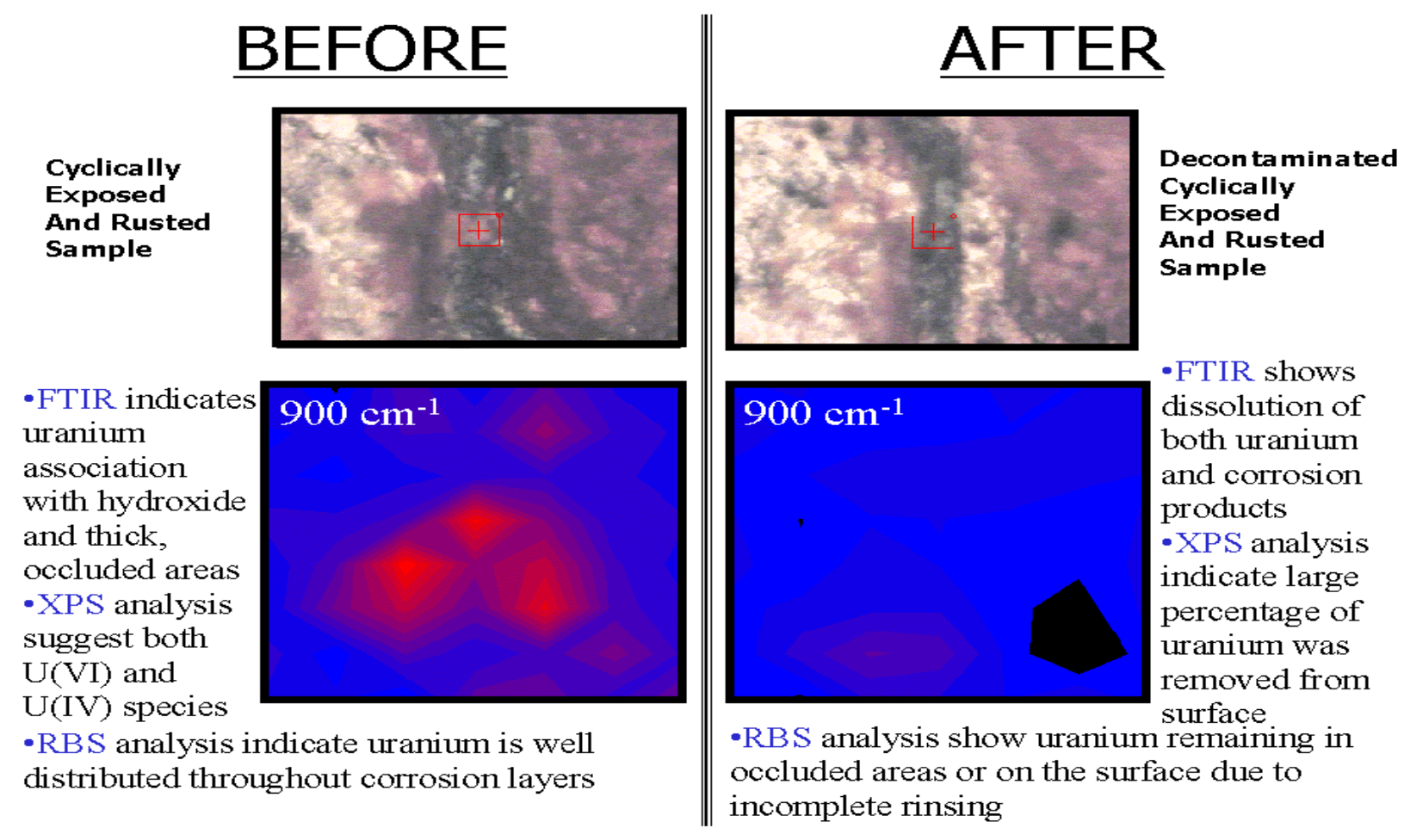

Figure 7. Optical images and FTIR maps of cyclically exposed and rusted carbon steel coupon before and after decontamination. This data is consistent with the uranium removal rates found for these classes of samples.

Analysis of the citric acid washed samples by FTIR microspectroscopy at the National Synchrotron Light Source (NSLS) showed that small amounts of residual U contaminant remained in heavily corroded areas. In areas where a thin yellow deposit was visible, FTIR indicated the presence of a complexed form of $U$ with a mixed $4^{+} / 6^{+}$character and strong IR absorption frequencies indicative of carboxylate salts. Additional absorption peaks within the spectra from these areas are being investigated and may indicate complexation with $\mathrm{Fe}$ corrosion products that were not removed by rinsing. A U-O stretching frequency indicative of purely $\mathrm{U}(\mathrm{VI})$ species (and very similar to published data for uranyl hydroxides) was detected from small amounts of residual $\mathrm{U}$ on dark corrosion products rich in magnetite. These areas represent the chemical sites of the most tenacious contaminants, and though lower in overall $\mathrm{U}$ retention levels (as compared to the incompletely removed complexed U described above), these are likely the strongest $\mathrm{U}$ binding sites.

The tenacity of uranium contamination on more heavily corroded samples can thus be attributed to: (i) increased amount of uranium contamination of these rough surfaces, (ii) presence of more highly crystallized forms of iron oxy-hydroxides and uranyl hydroxides (schoepite), which have a stronger complexation and chemical binding, and (iii) the occlusion and/or trapping of both contaminants and hard-to-rinse complex uranyl compounds. This suggests that decontamination techniques which loosen surface corrosion product scales, attack the more crystallized forms of mixed iron-uranium oxy-hydroxides (perhaps through ionexchange processes), and which are better at penetrating to occluded areas will enjoy the greatest degree of success in removing radiological contamination. 
Treatment of Decontaminated Solutions Containing Citric acid and Uranium. The concentrations of iron and uranium in the extract solutions following treatment of the low carbon steel coupon is shown in Table 3.

Table 3. Concentration of iron and uranium in decontamination solutions.

\begin{tabular}{lllll}
\hline Treatment & Citric acid & $\begin{array}{c}\text { Oxalic acid } \\
\text {--------- }\end{array}$ & $\begin{array}{l}\text { Iron } \\
\mathrm{mM}\end{array}$ & $\begin{array}{l}\text { Uranium } \\
\mu \mathrm{M}\end{array}$ \\
\hline Oxalate/peroxide/citrate & $7.3 \pm 0.2$ & $0.39 \pm 0.02$ & $2.26 \pm 0.33$ & $29.8 \pm 2.7$ \\
Citrate/peroxide/citrate & $8.3 \pm 0.4$ & --- & $1.81 \pm 0.23$ & $34.1 \pm 3.4$ \\
\hline
\end{tabular}

Biodegradation of the extract solutions containing citrate-peroxide-citrate or oxalateperoxide-citrate from decontamination of U-contaminated low carbon steel coupon resulted in complete removal of citric acid and iron from solution but not $U$ which remained in solution (Figure 8). The supernate containing uranium was filtered, the $\mathrm{pH}$ adjusted to 3.5 , and the solution was exposed to light. Uranium precipitated from solution and was recovered as uranium trioxide (Dodge and Francis, 1994). ). The oxalic acid was unaffected during biodegradation. However, photodegradation of the extract resulted in its oxidation to carbon dioxide and water.
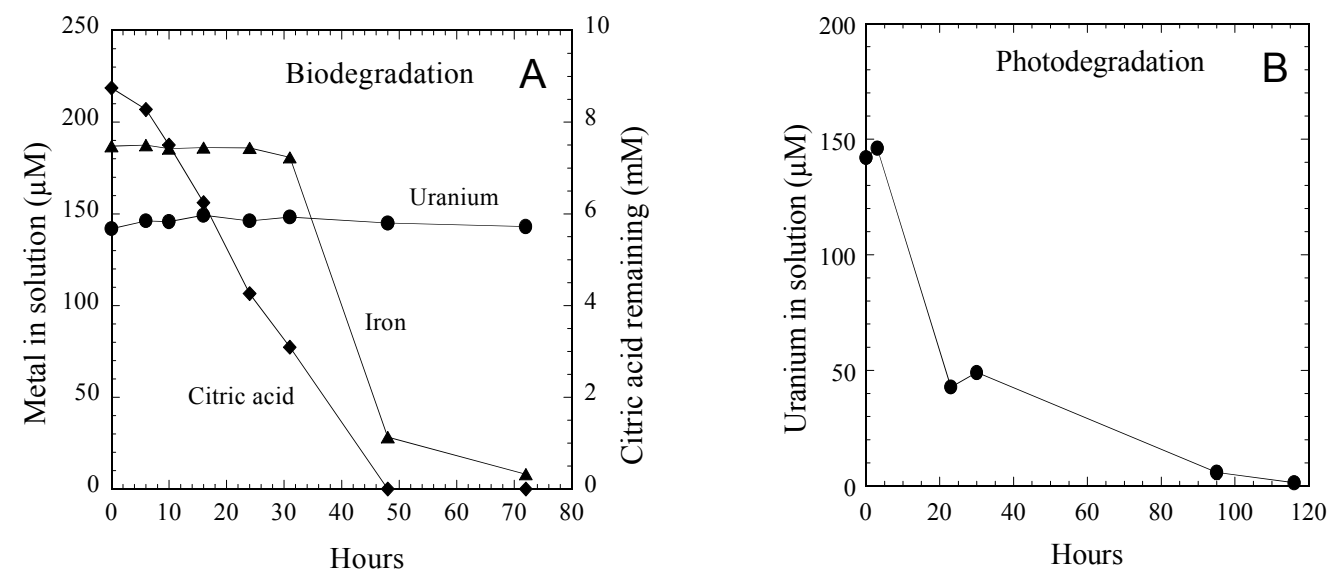

Figure 8. Treatment of citrate-peroxide-citrate decontamination solution by biodegradation and photodegradation with uranium recovery.

The use of organic acids to remove radionuclides from contaminated materials has a number of advantages including: (i) wet extraction which reduces dust formation, (ii) dissolution of oxides from the surface layer to remove fixed contamination including those coprecipitated with iron oxides, and (iii) the ability to penetrate porous materials to remove contamination located below the surface. Ultrasonic agitation, light or temperature activation may also play a role in accelerating the extraction of surface contaminants. The aqueous waste generated by this 
process can be remediated by photodegradation and/or biodegradation resulting in the precipitation and recovery of radionuclides in a concentrated form with volume reduction, which can be disposed of or recycled.

\section{RELEVANCE, IMPACT, AND TECHNOLOGY TRANSFER}

Though work has been performed in the past on interaction of uranium with metal filings or clean surfaces, this is the first program to address real-world concerns about how contaminant uranium interacts with and attaches to structural engineering materials in weathering environments. This knowledge is essential in both understanding and optimizing decommissioning and decontamination technologies, and hence will aid in reducing the associated costs and risks. By its very nature and experimental design, this project has as its goal bridging the gap between fundamental research and needs-driven applications of remediation technology. The data and conclusions developed in this work have shown it to be a successful approach and one worth emulating in the design of future programs.

This project has partially supported acquisition of an FTIR microspectroscopy system at SUNY Stony Brook which has significantly expanded the capabilities in molecular sciences and surface analysis. In addition, experience gained from this work has led to new research with uranium at Stony Brook, specifically in the area of corrosion inhibition of depleted uranium (currently funded by the Army Office of Scientific Research). Furthermore, the need to meet the stringent safety and security requirements of this program has enhanced the infrastructure of the PI's laboratory and created the opportunity to pursue further research in the field of radionuclide research in areas of value to DOE.

Two government contacts have expressed interest in the outcomes of this project: Richard Markland at the Army Research Laboratory, Weapons and Materiels Directorate (Aberdeen, Maryland). He is involved in storage and cleanup of depleted uranium at ARL, and is interested in how the proposed clean up technology can be applied to issues in his area. Dr. Dan Melamed, TRU/Mixed Waste Focus Area, US Department of Energy (EM-52) (TEL 202 586-6239), has expressed an interest in some of the uranium chemistry issues resulting from this work. In addition, a private company, Materials Characterization Laboratories, Inc. in Oak Ridge, TN, has also expressed interest. MCL is involved in both characterization studies and development of new decontamination methodologies. Discussions with this company are ongoing. Contacts at the company are Dr. William Bostick and Dr. Barry Stephenson.

\section{PROJECT PRODUCTIVITY}

Though significant knowledge was developed in this project, actual contaminated metal from DOE sites could not be obtained for characterization and decontamination using the methods and techniques developed in this work. Further analysis of data and development of chemical models which will lead to additional research publications is being conducted through a no-cost one year extension of the program at SUNY Stony Brook. Extensive spectroscopic databases acquired through on-going projects with the Army Research Laboratory will enhance our interpretation of this data and the resulting molecular models. 


\section{PERSONNEL SUPPORTED}

Dr. Gary P. Halada (one summer month effort per year)

Dr. Clive R. Clayton (one summer month effort per year)

Full time graduate students:

Anupama Gupta: 1998 - 1999 (left university for personal reasons)

Charlotte Eng: 2000 - present (MS, 2002; Ph.D. expected 2004)

\section{Partial graduate student support:}

Cleveland Dodge: 1999.

Thesis Title: Structural characterization of a ternary Fe(III)-U(VI)citrate complex. Ph.D. Dissertation. 1999. SUNY-SB, Stony Brook, NY.

Dev Chidambaram: 2002

\section{Undergraduates supported:}

Jason McDonald: 2000

John Sakal: 1999

Jeffrey Reingold: 2000

Michael Cuiffo: 2000 - 2001

Amy Kozer: 2000

Hao-Yu Lin: 2002

\section{PUBLICATIONS}

1 Dodge C. J. and A. J. Francis. 2002. Photodegradation of a ternary Fe(III)-U(VI)-citric acid complex. Environ. Sci. Technol. (in press).

2 Dodge, C.J., A.J. Francis, J.B. Gillow, G.P. Halada, C. Eng, and C.R. Clayton. Association of uranium with iron oxides typically formed on corroding steel surfaces. Submitted to Environmental Science and Technology (in review).

3 Eng C.W., Halada, G.P., A.J. Francis, C.J. Dodge and J.B. Gillow. A study of the association of contaminant uranium with carbon steel surfaces, [accepted for publication in Surface and Interface Analysis].

4 Halada G. P. and C. Clayton. Applications of synchrotron infrared microspectroscopy (SIRMS) to corrosion, contamination and coatings, in "State-of-the-Art Application of Surface and Interface Analysis Methods to Environmental Material Interactions: In Honor of James E. Castle's 65th Year", eds. D.Baer, C.R. Clayton, G. Davis and G. Halada, The Electrochemical Society, Pennington, N.J., (2001). 


\section{Manuscripts in preparation}

1. Francis, A.J., C.J. Dodge, J.A. McDonald and G.P. Halada, Decontamination of uraniumcontaminated steel surfaces by hydroxycarboxylic acids with uranium recovery.

2. Eng, C.W., G.P. Halada, A.J. Francis, C.J. Dodge and J.B. Gillow. Spectroscopic Study of Decontaminated Corroded Carbon Steel Surfaces.

\section{PRESENTATIONS AT NATIONAL MEETINGS}

3. Francis, A.J., C.J. Dodge, J.B. Gillow, G.P. Halada, and C.R. Clayton. Mechanisms of radionuclide-hydroxycarboxylic acid interactions for decontamination of metallic surfaces. Paper presented at the EMSP National Workshop 2000, April 24-28, 2000, Atlanta, GA.

4. Halada, G.P., C.R. Clayton, A. Gupta, A.J. Francis, C.J. Dodge and J.B. Gillow. Removal of contaminant uranium from corroded steel surfaces using citric acid. Paper presented at the $197^{\text {th }}$ Meeting of the Electrochemical Society, May 15-19, 2000, Toronto, Canada.

5. Halada, G.P., C.R. Clayton, A. Gupta, A.J. Francis, C.J. Dodge and J.B. Gillow. Removal of contaminant uranium from corroded steel surfaces using citric acid. Paper presented at the 1999 Tri-Service Conference on Corrosion, organized by the U.S. Army Research Laboratory, Aberdeen Proving Grounds, MD. Nov 15-19, 1999, Myrtle Beach, SC (Paper No. 0006).

6. Halada, G.P., C.R. Clayton, A. Gupta, A.J. Francis, C.J. Dodge and J.B. Gillow. A study of the interaction of contaminant uranium with atmospheric corrosion products on steel and subsequent complexation by hydroxycarboxylic acid. Paper presented at the 1999 Joint International Meeting, The Electrochemical Society and the Electrochemical Society of Japan, October 17-22, 1999, Honolulu, Hawaii (Abstract no. 617).

7. Francis, A.J., C.J. Dodge, J.B. Gillow, G.P. Halada, and C.R. Clayton. Decontamination of uranium contaminated metallic surfaces with uranium recovery. Paper presented at the Symposium on First Accomplishments of Environmental Management Science Program, $218^{\text {th }}$ American Chemical Society, Annual Meeting, August 22-26, 1999, New Orleans, LA, (paper NUCL-65).

8. Halada, G.P., C.R. Clayton, A. Gupta, J. Sakal, A.J. Francis, C.J. Dodge and J.B. Gillow. A spectroscopic study of the association of contaminant uranium with mild steel corrosion products. Paper presented at the 218th Annual ACS Meeting, First Accomplishments of the EMSP, New Orleans, 1999.

9. Francis, A.J., C.J. Dodge, J.B. Gillow, et al., "Decontamination of uranium-contaminated metallic surfaces with uranium recovery", Abstr. Pap. Am. Chem. Soc. 218: U1055-U1055 Part 1 Aug 221999.

10. Halada, G.P., C.R. Clayton, A.J. Francis, et al. "Spectroscopic study of the association of contaminant uranium with mild steel corrosion products", Abstr. Pap. Am. Chem. Soc. 218: U1045-U1045 Part 1 Aug 221999.

11. Halada, G.P., C.R. Clayton, M.J. Vasquez, A. Gupta, A.J. Francis, C.J. Dodge and J.B. Gillow. Interaction of uranium with corrosion products formed on plain carbon steel. Paper presented at the $195^{\text {th }}$ Meeting of the Electrochemical Society, May 2-6, 1999, Seattle, WA (Abstract. No. 108). 
12. Halada, G.P., C. Eng, A.J. Francis, C.J. Dodge and J. B. Gillow, Mechanisms of interaction of uranium with corroded steel surfaces, Abstract 116, 222 ${ }^{\text {nd }}$ ACS National Meeting, Chicago, IL, August 26-30, 2001.

13. Dodge, C.J., A.J. Francis, J.B. Gillow, G.P. Halada and C. Eng, Association of uranium with iron oxides commonly found on corroding steel surfaces, Abstract 117, $222^{\text {nd }}$ ACS National Meeting, Chicago, IL, August 26-30, 2001.

14. Francis, A.J., C.J. Dodge, J.A. McDonald and G.P. Halada, Decontamination of uraniumcontaminated steel surfaces by hydroxycarboxylic acids with uranium recovery, Abstract 161, 222 $2^{\text {nd }}$ ACS National Meeting, Chicago, IL, August 26-30, 2001.

15. Halada, G. P. C. Clayton, M. Cuiffo, C. Eng, A. Francis, C. Dodge and J. Gillow, An optical and electron spectroscopic study of the decontamination of corroded steel surfaces exposed to radionuclides using hydroxycarboxylic acids", $199^{\text {th }}$ meeting of the Electrochemical Society, March 25-30, 2001, Washington D.C.

16. Dodge, C.J., A.J. Francis, and J.B. Gillow, G.P. Halada, C. Eng, and C.R. Clayton, Association of uranium with iron oxides typically formed on corroding steel surfaces. Presented at Synchrotron Environmental Science II (SES-II) Argonne National Laboratory May 6-8, 2002.

\section{TRANSITIONS}

The infrared and X-ray photoelectron spectroscopy spectral database developed in this work is being used at SUNY Stony Brook to support further environmental research and further research on depleted uranium corrosion by the PI.

\section{FUTURE WORK}

Fundamental processes that could facilitate volumetric reduction of waste from D\&D activities have not been fully investigated. Secondary waste minimization by treatment of citric acid extract solution containing radionuclides is an important component of the overall decontamination strategy. Aqueous waste containing citric acid from decontamination of radionuclide-contaminated surfaces can be treated microbiologically to minimize secondary waste generation.

- The speciation of $U$ in solution after biodegradation, whether it is complexed with an organic compound (citric acid, microbial metabolite) or as carbonate complex, is not known. Therefore, the exact mechanism for its photodegradation has not been elucidated. Optimization of the process parameters for the biodegradation of metal citrate complexes and the photochemical recovery of $U$ from the decontaminated solutions should make this process more attractive and cost effective.

- Determine the effect of and fate of other co-contaminants such as Co, Mo, and paint residues on biodegradation of the decontaminated solution and recovery of $\mathrm{U}$ by photochemical precipitation.

- Determine the association of contaminant uranium with other surfaces, including stainless steel, copper and painted surfaces, in order to provide data for optimization of decontamination methodologies.

- Acceleration and optimization of photodegradation of U by visible and UV light. 
- Recovery and recycling of citric acid to reduce chemical cost and make the process more economical.

\section{LITERATURE CITED}

Allen, P.G., D.K. Shuh, J.B. Bucher, N.M. Edelstein, T. Reich, M.A. Denecke, H. Nitsche. 1996. EXAFS determinations of uranium structures: Uranyl complexed with tartaric, citric, and malic acids. Inorg. Chem., 35:784-787.

Brooks, A.R., C.R. Clayton, K. Doss; and Y.C. Lu. 1986. On the role of Cr in the passivity of stainless steel. J. Electrochem. Soc., 133(12):2459-2464.

Dodge, C.J. and A.J. Francis. 1994. Photodegradation of uranium-citrate complex with uranium recovery. Environ. Sci Technol., 31:3062-3067.

Dodge, C.J and A.J. Francis. 1997. Biotransformation of binary and ternary citric acid complexes of iron and uranium. Environ. Sci Technol., 28:1300-1306.

Dodge, C.J., A.J. Francis, G.P. Halada. C.R. Clayton. Association of uranium with iron oxides typically formed on corroding steel surfaces. Submitted to Environ. Sci. Technol..

Dodge, C.J.; A.J. Francis. 2002. Photodegradation of a ternary Fe(III)-U(VI)-citric acid complex. Accepted for publication in Environ. Sci. Technol.

Francis, A.J., C.J. Dodge, J.B. Gillow. 1992. Biodegradation of metal citrate complexes and implications for toxic-metal mobility. Nature (London) 356:140-142.

Francis, A.J., Dodge, C.J., Gillow, J.B., Papenguth, H.W. 2000. Biotransformation of uranium compounds in high ionic strength brine by a halophilic bacterium under denitrifying conditions. Environ. Sci. Technol., 34:2311-2317.

Ishikawa, T., Nakazaki, H., Yasukawa, A., Kandori, K., Seto, M. 1999. Influences of $\mathrm{Co}^{2+}, \mathrm{Cu}^{2+}$, and $\mathrm{Cr}^{3+}$ ions on the formation of magnetite. Corros. Sci. , 41: 1665-1672.

Liger, E., L. Charlet. P., van Cappellen. 1999. Surface catalysis of uranium(VI) reduction by iron(II). Geochim. Cosmochim. Acta, , 63(19/21):2939-2955.

Misawa, T., Hashimoto, K., Suetaka, W., Shimodaira, S. Mechanism of formation of iron oxide and oxyhydroxides in aqueous solutions. In Proceedings of the Fifth International Congress on Metallic Corrosion, Tokyo, Japan, May 1972, NACE: Houston, Texas (1974), p. 775.

Moyes, L.N., Parkman, R.H., Charnock, J.M., Vaughn, D.J., Livens, F.R.; Hughes, C.R.; Braithwaite, A. 2000. Uranium uptake from aqueous solution by interaction with goethite, lepidocrocite, muscovite, and mackinawite: An X-ray absorption spectroscopy study. Environ. Sci. Technol., 34:1062-1068.

Refait, P.; Abdelmoula, M.; Genin, J.-M.R. 1998. Mechanism of formation and structure of green rust one in aqueous corrosion of iron in the presence of chloride ions. Corros. Sci., 40:1547-1560.

Waite, T.D., Davis, J.A., Payne, T.E., Waychunas, G.A., Xu, N. 1994. Uranium(VI) adsorption to ferrihydrite: Application of a surface complexation model. Geochim. Cosmochim. Acta, 58:5465-5478.

Wells, A.F. In Structural Inorganic Chemistry. $4^{\text {th }}$ Ed., Clarendon Press, Oxford, 1975, p. 1003. 